e-issn : 2622-0148, p-issn : 2087-0035

\title{
HUBUNGAN DUKUNGAN KELUARGA DENGAN KETERATURAN KONTROL KADAR GULA DARAH PADA PENDERITA DIABETES MELLITUS TIPE II DI WILAYAH KERJA PUSKESMAS MANGASA KEC. RAPPOCINI KOTA MAKASSAR
}

\author{
Relation Of Family Support With Regularity Of Control Of Blood Sugar Level In Type li Diabetes Mellitus At \\ Mangasa Public Health Center Rappocini Makassar City.
}

\author{
M. Yusuf', Hamsiah Hamzah², Hariani ${ }^{3}$, Hastina Melinda ${ }^{4}$ \\ Poltekkes Kemenkes Makassar \\ Program Studi D.IV Keperawatan \\ Email : Hastinamelinda2@gmail.com \\ No, Telp : 085256721220
}

\begin{abstract}
Diabetes mellitus is a chronic condition characterized by an increase in blood glucose concentration with the emergence of typical main symptoms, namely urine that taste sweet in large numbers therefore the support of families is needed because it is an important factor in compliance management chronic illness for teenagers and adults. Family support is a powerful indicator that can provide a positive impact on self-care in patients with diabetes. The purpose of this study is to determine the relationship of family support with regularity control of blood sugar levels in patients with Diabetes Mellitus Type II in the work area of Mangasa Kec.Rappocini Puskesmas Makassar. Research Method: This research type is descriptive analysis research with cross sectional design. Population and sample in this research that is patient of Diabetes Mellitus which amounted to 22 people with sampling technique that is Saturated Sampling. Data collection was done by giving questionnaires to people with Diabetes Mellitus. Data analysis using Chi Sqaure with significance level $\alpha=0,05$. Results of research for family support were $90.9 \%$ and support of less than $9.1 \%$. The results of the study for the regularity of blood sugar control by $90.9 \%$ and irregular by $9.1 \%$. From the results of statistical tests can be concluded that there is a relationship between family support with regularity control blood sugar levels ( $p$ value 0.004).
\end{abstract}

Keywords: Family Support, Blood Sugar Control Blood, Diabetic Mellitus

\begin{abstract}
ABSTRAK
Diabetes mellitus merupakan kondisi kronis yang ditandai dengan peningkatan konsentrasi glukosa darah disertai munculnya gejala utama yang khas, yakni urine yang berasa manis dalam jumlah yang besar oleh karena itu dukungan keluarga sangat dibutuhkan karena merupakan suatu faktor yang penting dalam kepatuhan manajemen penyakit kronik untuk remaja maupun dewasa. Dukungan keluarga merupakan indikator yang kuat yang dapat memberikan suatu dampak positif terhadap perawatan diri pada pasien dengan diabetes. Tujuan penelitian ini yaitu untuk mengetahui hubungan dukungan keluarga dengan keteraturan kontrol kadar gula darah pada penderita Diabetes Mellitus Tipe II di wilayah kerja Puskesmas Mangasa Kec.Rappocini Kota Makassar. Metode Penelitian : Jenis penelitian ini merupakan penelitian bersifat analisis deskriptif dengan desain cross sectional. Populasi dan sampel dalam penelitian ini yaitu penderita Diabetes Mellitus yang berjumlah 22 orang dengan tehnik pengambilan sampel yaitu Sampling Jenuh. Pengumpulan data dilakukan dengan memberikan kuesioner kepada penderita Diabetes Mellitus. Analisis data menggunakan Chi Sqaure dengan tingkat bermakna a $=0,05$. Hasil penelitian untuk dukungan keluarga sebesar $90,9 \%$ dan dukungan yang kurang sebesar $9,1 \%$. Adapun hasil penelitian untuk keteraturan kontrol gula darah sebesar 90,9\% dan yang tidak teratur sebesar 9,1\%. Dari hasil uji statistik dapat disimpulkan bahwa ada hubungan antara dukungan keluarga dengan keteraturan kontrol kadar gula darah ( $p$ value 0,004 ).
\end{abstract}

Kata Kunci : Dukungan Keluarga, Keteraturan Kontrol Gula Darah, Diabetes Melitus

\section{PENDAHULUAN}

Seiring dengan perkembangan zaman, pola penyakit yang diderita telah bergeser dari penyakit infeksi dan kekurangan gizi kearah penyakit degeratif yang salah satunya adalah diabetes mellitus. Menurut
Kementerian Kesehatan Republik Indonesia (KEMENKES RI) tahun 2014. Estimasi terakhir International Diabetes Federation (IDF), terdapat 384 juta orang yang hidup dengan diabetes mellitus di 
dunia pada tahun 2013 (Salindeho, Mulyadi, \& Rottie, 2016).

Word Health Organization (WHO,2016) memperkirakan bahwa secara global, 422 juta orang dewasa berusia diatas 18 tahun yang hidup dengan diabetes pada tahun 2014. Interntional Diabetes Federation (IDF,2015) yang enyatakan terdapat 415 juta orang yang hidup dengan diabetes di dunia pada tahun 2015, pada tahun 2040 jumlah tersebut akan meningkat menjadi 642 juta orang. Selain itu adapun estimasi terakhir dari International Diabetes Federation (IDF, 2017) yang menyatakan terdapat 425 juta orang yang berusia 20-79 tahun yang hidup dengan diabetes mellitus di dunia pada tahun 2017, pada tahun 2045 jumlah terseebut diperkirakan meningkat menjadi 629 orang.

Indonesia merupakan salah satu Negara berkembang di dunia bagian Asia Tenggara dan mengalami peningkatan jumlah penderita diabetes mellitus, dimana pada tahun 2015 Indonesia menempati peringkat ke 7 dengan prevalensi penderita diabetes 10 juta (IDF, 2015) dan meningkat pada tahun 2017 dimana jumlah penderita diabetes di Indonesia menempati peringkat ke 6 dengan prevalensi penderita diabetes melitus usia 20-70 tahun pada tahun 2017 mencapai 10,3 juta orang diperkirakan akan meningkat pada tahun 2045 menjadi 16,7 juta orang (IDF, 2017).

Menurut hasil Riskesdas Tahun 2013 Prevalensi diabetes di Sulawesi Selatan yang didiagnosis dokter sebesar 1,6 persen dan 0,5 persen. DM yang didiagnosis dokter atau berdasarkan gejala sebesar 3,4 persen. Prevalensi diabetes yang didiagnosis dokter tertinggi terdapat di Kabupaten Pinrang (2,8\%), Kota Makassar (2,5\%), Kabupaten Toraja Utara (2,3\%) dan Kota Palopo (2,1\%). Prevalensi diabetes yang didiagnosis dokter atau berdasarkan gejala, tertinggi di Kabupaten Tana Toraja $(6,1 \%)$, Kota Makassar $(5,3 \%)$, Kabupaten Luwu $(5,2 \%)$ dan Kabupaten Luwu Utara $(4,0 \%)$ (syahril \& dkk. 2014). Peningkatan kasus DM juga terjadi di tingkat kabupaten/kota, khususnya di kota Makassar. Diabetes Melitus menempati peringkat ke lima dari sepuluh peyebab utama kematian di Makassar tahun 2007 dengan jumlah sebanyak 65 kasus. Berdasarkan data dari Dinas Kesehatan Kota Makassar, angka kejadian penyakit diabetes melitus pada tahun 2011 yaitu 5700 kasus. Pada tahun 2012 angka kejadian kasus DM meningkat menjadi 14.067 kasus, pada tahun 2013 menjadi 14.604 kasus dan semakin meningkat di tahun 2014 menjadi 21.452 kasus (Dinkes Kota Makassar, 2015).
Hasil penelitian Priharionto (2014) dengan judul penelitian hubungan dukungan keluarga degan keteraturan kontrol kadar gula darah pada penderita diabetes mellitus di wilayah kerja Puskesmas Bendosari Sukoharjo bahwa deskripsi hasil penelitian berdasarkan dukungan keluarga terhadap responden yang menderita DM di wilayah Puskesmas Bendosari bahwa dari 89 responden, sebanyak 22 responden $(24,7 \%)$ mendapat dukungan yang baik dari keluarga, 46 responden $(51,7 \%)$ mendapat dukungan yang cukup dari keluarga, dan 21 rsponden $(23,6 \%)$ mendapat dukungan yang kurang dari keluarga. Dari hasil penelitian ini dapat di asumsikan bahwa pasien DM yang berkunjung di Puskesmas Bendosari sebagian besar mendapatkan dukungan dari keluarga.

Hasil penelitian bahwa terdapat hubungan dukungan keluarga dengan keteraturan kontrol kadar gula darah pada penderita DM di wilayah Kerja Puskesmas Bendosari juga di dukung oleh penelitian terdahulu yaitu, penelitian dari Albherta (2012) yang menyatakan bahwa faktor yang mempengaruhi keteraturan kontrol kadar gula darah yaitu tingkat pendidikan, waktu atau jarak tempuh, disertai dengan dukungan keluarga dan dukungan tenaga kesehatan.

Studi penelitan telah membuktikan bahwa pasien diabetes mellitus yang melakukan kontrol kadar gula darah secara teratur memiliki kualitas hidup yang baik dan juga memiliki resiko komplikasi yang lebih rendah (Priharianto, 2014). Sehingga perlunya dukungan keluarga terhadap pasien diabetes mellitus dalam melakukan kunjungan kontrol gula darah.

Jumlah data yang diperoleh pengunjung diabetes mellitus di wilayah kerja Puskesmas Mangasa Kec. Rappocini Kota Makassar berjumlah 22 penderita yang berkunjung untuk melakukan pengobatan pada bulan februari tahun 2018.

Berdasarkan latar belakang di atas penulis tertarik untuk melakukan penelitian tentang " Hubungan Dukungan Keluarga Dengan Keteraturan Kontrol Kadar Gula Darah Pada Penderita Diabetes Mellitus Tipe II Wilyah Kerja Puskesmas Mangasa Kec. Rappocini Kota Makassar".

\section{METODE}

\section{Desain, tempat dan waktu}

Penelitian ini bersifat analisis deskriptif dengan desain cross sectional. Cross Sectional yaitu rancangan penelitian dengan melakukan pengukuran atau pengamatan pada saat bersamaan, atau yang melakukan pemeriksaan status paparan dan status penyakit pada titik yang sama. Penelitian 
Vol. 08. No.02. 2017

e-issn : 2622-0148, p-issn : 2087-0035

ini di lakukan di Wilayah Kerja Puskesmas Mangasa Kec. Rappocini Kota Makassar.

\section{Jumlah dan cara pengambilan subjek atau bahan} dan alat

Populasi dalam penelitian ini adalah 22 pasien diabetes mellitus Tipe II yang yang berada di wilayah kerja Puskesmas Mangasa Kec. Rappocini Kota Makassar dan Jumlah sampel dalam penelitian ini yaitu 22 responden. Jumlah sampel diambil dari keseluruhan jumlah populasi (jumlah populasi sama dengan jumlah sampel). Teknik sampling yang digunakan pada penelitian ini adalah teknik Sampling Jenuh. Sampling jenuh mengambil semua anggota populasi untuk dijadikan sampel.

Instrumen penelitian ini menggunakan kuesioner yang terdiri dari kuesioner karakteristik demografi responden, kuesioner dukungan keluarga dan keteraturan kontrol gula darah.

Analisa data menggunakan analisis uivariat dan analisis bivariate. Analisis bivariate melalui uji statistic yaitu menggunakan uji Chis Quare Analisa data menggunakan analisis uivariat dan analisis bivariate. Analisis bivariate melalui uji statistic yaitu menggunakan uji Chis Quare

\section{HASIL}

1. Gambaran Umum Responden

Tabel 4.1

Distribusi Frekuensi Responden Menurut Umur di Puskesmas Mangasa Kec. Rappocini Kota Makassar 2018

\begin{tabular}{ccc}
\hline Umur & \multicolumn{2}{c}{ Jumlah } \\
\cline { 2 - 3 } & $\mathbf{F}$ & $\%$ \\
\hline $31-40$ tahun & 1 & $4,5 \%$ \\
\hline $41-50$ tahun & 6 & $27,3 \%$ \\
\hline $51-60$ tahun & 9 & $40,9 \%$ \\
\hline $61-70$ tahun & 6 & $27,3 \%$ \\
\hline Total & 22 & $100 \%$ \\
\hline
\end{tabular}

Sumber : Data primer

Berdasarkan tabel 4.1 dapat diketahui bahwa penderita diabetes mellitus di Puskesmas Mangasa Kec. Rappocini Kota Makassar rata-rata berusia 51-60 tahun 9 orang (40,9\%), sedangkan yang berusia 41-50 dan $61-70$ tahun masing-masing 9 orang $(27,3 \%)$, dan $31-40$ tahun 1 orang $(4,5 \%)$.
Tabel 4.2

Distribusi Frekuensi Responden Menurut Jenis Kelamin di Wilayah Kerja Puskesmas Mangasa Kec. Rappocini Kota Makassar 2018

\begin{tabular}{ccc}
\hline Jenis Kelamin & \multicolumn{2}{c}{ Jumlah } \\
\cline { 2 - 3 } & $\mathbf{f}$ & $\%$ \\
\hline Perempuan & 18 & $81,8 \%$ \\
\hline Laki-laki & 4 & $18,2 \%$ \\
\hline Total & 22 & $100 \%$ \\
\hline
\end{tabular}

Sumber : Data primer

Berdasarkan tabel 4.1 dapat diketahui bahwa penderita diabetes mellitus di wilayah kerja Puskesmas Mangasa Kec.Rappocini Kota Makassar sebagian besar berjenis kelamin perempuan sebanyak 18 orang $(81,8 \%)$, dan sebagian kecil berjenis kelamin laki-laki sebanyak 4 orang $(18,2 \%)$.

Tabel 4.3

Distribusi Frekuensi Responden Menurut

Pendidikan di di Wilayah Kerja Puskesmas

Mangasa Kec. Rappocini Kota Makassar 2018

\begin{tabular}{ccc}
\hline Pendidikan & \multicolumn{2}{c}{ Jumlah } \\
\cline { 2 - 3 } & $\mathrm{F}$ & $\%$ \\
\hline SD & 2 & $9,1 \%$ \\
\hline SMA & 13 & $59,1 \%$ \\
\hline Perguruan Tinggi & 7 & $31,8 \%$ \\
\hline Total & 22 & $100 \%$ \\
\hline
\end{tabular}

Sumber : Data Primer

Berdasarkan tabel 4.4 dapat diketahui bahwa penderita diabetes mellitus di Wilayah Kerja Puskesmas Mangasa Kec. Rappocini Kota Makassar untuk tingkat pendidikan yaitu lulusan SD sebanyak 2 orang $(9,1 \%)$, dan lulusan SMA sebanyak 13 orang $(59,1 \%)$, dan lulusan perguruan tinggi 7 orang $(31,8 \%)$.

Tabel 4.4

Distribusi Frekuensi Responden Menurut Komplikasi di di Wilayah Kerja Puskesmas Mangasa Kec. Rappocini Kota Makassar 2018

\begin{tabular}{ccc}
\hline \multirow{2}{*}{ Komplikasi } & \multicolumn{3}{c}{ Jumlah } \\
\cline { 2 - 3 } & $\mathrm{F}$ & $\%$ \\
\hline Ada & 12 & $54,5 \%$ \\
\hline Tidak Ada & 22 & $45,5 \%$ \\
\hline Total & $100 \%$ \\
\hline Sumber : Data primer \\
Berdasarkan tabel 4.4 dapat diketahui bahwa \\
penderita diabetes mellitus di wilayah kerja Puskesmas \\
Mangasa Kec. Rappocini Kota Makassar untuk tingkat \\
komplikasi yaitu, yang memiliki komplikasi berjumlah 12
\end{tabular}


orang $((54,5 \%)$, dan yang tidak memiliki komplikasi berjumlah 10 orang $(45,5 \%)$.

Tabel 4.5

Distribusi Frekuensi Responden Menurut Lama Menderita Diabetes Mellitus di Wilayah Kerja Puskesmas Mangasa Kec. Rappocini Kota Makassar 2018

\begin{tabular}{ccc}
\hline Kategori lama menderita DM & \multicolumn{2}{c}{ Jumlah } \\
\cline { 2 - 3 } & $\mathbf{F}$ & $\%$ \\
\hline 1 & 5 & $22.7 \%$ \\
\hline 2 & 8 & $36,4 \%$ \\
\hline 3 & 2 & $9,1 \%$ \\
4 & 3 & $13,6 \%$ \\
5 & 3 & $13,6 \%$ \\
23 & 1 & $4,5 \%$ \\
Total & 22 & $100 \%$ \\
\hline
\end{tabular}

Sumber : Data Primer

Berdasarkan tabel 4.4 dapat diketahui bahwa penderita diabetes mellitus di wilayah kerja puskesmas mangasa Kec. Rappocini Kota Makassar untuk lama menderita diabetes mellitus 1 tahun sebanyak 5 orang $(22,7 \%), 2$ tahun sebanyak 8 orang $(36,4 \%), 3$ tahun sebanyak 2 orang $(9,1 \%), 4$ tahun sebanyak 3 orang $(13,6 \%), 5$ tahun sebanyak 3 orang $(9,1 \%)$, dan 23 tahun sebanyak 1 orang $(4,5 \%)$.

Tabel 4.6

Distribusi Frekuensi Responden Menurut Riwayat Diabetes Mellitus di Wilayah Kerja Puskesmas Mangasa Kec. Rappocini Kota Makassar 2018

\begin{tabular}{ccc}
\hline Kategori Menderita & \multicolumn{2}{c}{ Jumlah } \\
\cline { 2 - 3 } Diabetes Mellitus & $\mathbf{F}$ & $\%$ \\
\hline Ada & 10 & $45,5 \%$ \\
\hline Tidak ada & 12 & $54,5 \%$ \\
\hline Total & 22 & $100 \%$ \\
\hline
\end{tabular}

Sumber : Data primer

Berdasarkan tabel 4.5 dapat diketahui bahwa penderita diabetes mellitus di wilayah kerja Puskesmas Mangasa Kec.Rappocini Kota Makassar untuk riwayat diabetes melitus terdapat 10 orang $(45,5 \%)$ yang memiliki riwayat diabetes mellitus, dan 12 orang $(54,5 \%)$ yang tidak memiliki riwayat keluarga yang terkena diabetes mellitus.

\section{Analisis Univariate}

a. Dukungan kelurga
Tabel 4.7

Distribusi Frekuensi Responden Menurut Dukungan Keluarga di Wilayah Kerja Puskesmas Mangasa Kec. Rappocini Kota Makassar 2018

\begin{tabular}{ccc}
\hline $\begin{array}{c}\text { Kategori Dukungan } \\
\text { Keluarga }\end{array}$ & \multicolumn{2}{c}{ Jumlah } \\
\cline { 2 - 3 } & $\mathbf{F}$ & $\%$ \\
\hline Mendukung & 20 & $90,9 \%$ \\
\hline Kurag mendukung & 22 & 9,1 \\
\hline Total & $100 \%$ \\
\hline Sumber : Data primer \\
Berdasarkan tabel 4.6 dapat diketahui bahwa \\
penderita diabetes mellitus di wilayah kerja Puskesmas \\
Mangasa Kec.Rappocini & Kota Makassar untuk \\
dukungan keluarga yaitu 20 orang memiliki dukungan \\
keluarga yang mendukung (90,9\%), dan yang kurang \\
mendukung 2 orang (9,1\%). \\
Berdasarkan hasil penelitian yang diperoleh
\end{tabular}
dari 22 orang penderita diabetes mellitus di wilayah kerja Puskesmas Mangasa Kec.Rappocini Kota Makassar lebih besar memiliki dukungan kelurga yang mendukung dengan kisaran berjumlah 22 orang dengan $90,9 \%$, sedangkan dukungan keluarga yang kurag mendukung berjumlah 2 orang dengan 9,1\%. Hal ini menunjukkan lebih besar penderita diabetes mellitus memiliki dukungan keluarga yang mendukung yang berada di wilayah kerja Puskesmas Mangasa Kec. Rappocini Kota Makassar.

Penelitian ini dibuktikan oleh peniliti yang telah dilakukan oleh Periharianto dengan judul penelitian hubungan dukungan keluarga degan keteraturan kontrol kadar gula darah pada penderita diabetes mellitus di wilayah kerja Puskesmas Bendosari Sukoharjo bahwa Hasil penelitian bahwa terdapat hubungan dukungan keluarga dengan keteraturan kontrol kadar gula darah . hasil penelitian berdasarkan dukungan keluarga terhadap responden yang menderita DM di wilayah Puskesmas Bendosari bahwa dari 89 responden, sebanyak 22 responden $(24,7 \%)$ mendapat dukungan yang baik dari keluarga, 46 responden $(51,7 \%)$ mendapat dukungan yang cukup dari keluarga, dan 21 rsponden $(23,6 \%)$ mendapat dukungan yang kurang dari keluarga. Dari hasil penelitian ini dapat di asumsikan bahwa pasien DM yang berkunjung di Puskesmas Bendosari sebagian besar mendapatkan dukungan dari keluarga

Berdasarkan hasil penelitian diatas sesuai dengan teori yang menyatakan bahwa Dukungan keluarga didefinisikan sebagai suatu faktor yang penting dalam kepatuhan manajemen penyakit kronik untuk remaja maupun dewasa. Dukungan keluarga merupakan indikator yang kuat yang dapat memberikan suatu dampak positif terhadap perawatan diri pada 
Vol. 08. No.02. 2017

e-issn : 2622-0148, p-issn : 2087-0035

pasien dengan diabetes (Hensarling, 2009), karena dalam dukungan keluarga terdapat berbagai jenis dukungan keluarga yang sangat berpengaruh yaitu, Dukungan instrumental, yaitu keluarga merupakan sumber pertolongan ptaktis dan konkrit diantaranya : bantuan langsung dari orang yang diandalkan seperti materi, tenaga dan sarana.

Manfaat dukungan ini adalah mendukung pulihnya energi atau stamina dan semangat yang menurun selain individu merasa bahwa masih ada perhatian atau kepedulian dari linkungan terhadap seseorang yang sedang mengalami kesusahan atau penderitaan sehingga dukungan instrumental ini sangat berpengaruh dengan keteraturan pasien dalam mengontrol kadar gula darah nya.Dukungan informasional yaitu keluarga berfungsi sebagai sebuah kolektor dan disseminator (penyebar informasi) tentang dunia yang dapat digunakan untuk mengungkapkan suatu masalah. Manfaat dari dukungan ini adalah dapat menekan munculnya suatu stressor karena informasi yang diberikan dapat menyumbangkan aksi sugesti yang khusus pada individu. Aspek-aspek dalam dukungan ini adalah nasehat, ususlan, saran, petunjuk dan pemberian informasi. b. Keteraturan Kontrol

Tabel 4.8

Distribusi Frekuensi Responden Menurut Keteraturan Kontrol Gula Darah di Wilayah Kerja Puskesmas Mangasa Kec. Rappocini Kota Makassar 2018

\begin{tabular}{ccc}
\hline $\begin{array}{c}\text { Kategori Keteraturan } \\
\text { Kontrol }\end{array}$ & $\mathbf{2}$ Jumlah \\
\cline { 2 - 3 } & $\mathbf{F}$ & $\%$ \\
\hline Teratur & 20 & $90,9 \%$ \\
\hline Tidak teratur & 22 & $100 \%$ \\
\hline Total & \\
\hline Sumber : Data primer \\
Berdasarkan tabel 4.6 dapat diketahui bahwa \\
penderita diabetes mellitus di wilayah kerja Puskesmas \\
Mangasa Kec. Rappocini Kota Makassar untuk \\
keteraturan kontrol kadar gula darah yaitu teratur 20 \\
orang (90,9\%) dan tidak teratur 2 orang (9,1\%).
\end{tabular}

3. Analisa Bivariat

a. Hubungan Dukungan Keluarga Dengan Keteraturan Kontrol Kadar Gula Darah

Tabel 4.9

Hubungan Dukungan Keluarga Dengan Keteraturan Kontrol Kadar Gula Darah Pada Penderita Diabetes Mellitus Di Wilayah Kerja Puskesmas Mangasa Kec. Rappocini Kota Makassar 2018

\begin{tabular}{|c|c|c|c|c|c|c|}
\hline \multirow{3}{*}{$\begin{array}{l}\text { Dukungan } \\
\text { Keluarga }\end{array}$} & \multicolumn{5}{|c|}{ Keteraturan Kontrol } & \multirow[t]{2}{*}{ Total } \\
\hline & \multicolumn{2}{|c|}{ Teratur } & \multicolumn{2}{|c|}{ Tidak Teratur } & & \\
\hline & $f$ & $\%$ & $\mathbf{F}$ & $\%$ & $\mathbf{F}$ & $\%$ \\
\hline Mendukung & 20 & $100 \%$ & 0 & 0,0 & 20 & $100,0 \%$ \\
\hline $\begin{array}{c}\text { Kurang } \\
\text { mendukung }\end{array}$ & 0 & $0,0 \%$ & 2 & $100 \%$ & 2 & $100,0 \%$ \\
\hline Total & 20 & $90,9 \%$ & 2 & $9,1 \%$ & 22 & $100 \%$ \\
\hline primer & & & & has $\mathrm{Mc}$ & $\mathrm{a} \mathrm{Ke}$ & appocini \\
\hline
\end{tabular}

Berdasarkan tabel 4.7 diperoleh hasil bahwa hubungan dukungan keluarga dengan keteraturan kontrol kadar gula darah pada penderita diabetes mellitus di wilayah kerja Puskesmas Mangasa Kec. Rappocini Kota Makassar mendukung 20 orang dengan $(100 \%)$ dan teratur kontrol gula darah, sedangkan dukungan keluarga dengan kurang mendukung 2 orang dengan (100\%) dan tidak teratur.

Hasil uji statistic (Chi Square) diketahui bahwa terdapat hubungan yang bermakna antara dukungan keluarga dengan keteraturan kontrol kadar gula darah penderita diabetes mellitus di wilayah kerja

\section{PEMBAHASAN}

\section{Univariat}

a. Dukungan Keluarga

Berdasarkan hasil penelitian yang diperoleh dari 22 orang penderita diabetes mellitus di wilayah kerja Puskesmas Mangasa Kec.Rappocini Kota Makassar lebih besar memiliki dukungan kelurga yang mendukung dengan kisaran berjumlah 22 orang dengan $90,9 \%$, sedangkan dukungan keluarga yang kurag mendukung berjumlah 2 orang dengan $9,1 \%$. Hal ini menunjukkan lebih besar penderita diabetes mellitus 
Vol. 08. No.02. 2017

e-issn : 2622-0148, p-issn : 2087-0035

memiliki dukungan keluarga yang mendukung yang berada di wilayah kerja Puskesmas Mangasa Kec. Rappocini Kota Makassar.

Penelitian ini dibuktikan oleh peniliti yang telah dilakukan oleh Periharianto dengan judul penelitian hubungan dukungan keluarga degan keteraturan kontrol kadar gula darah pada penderita diabetes mellitus di wilayah kerja Puskesmas Bendosari Sukoharjo bahwa Hasil penelitian bahwa terdapat hubungan dukungan keluarga dengan keteraturan kontrol kadar gula darah . hasil penelitian berdasarkan dukungan keluarga terhadap responden yang menderita DM di wilayah Puskesmas Bendosari bahwa dari 89 responden, sebanyak 22 responden $(24,7 \%)$ mendapat dukungan yang baik dari keluarga, 46 responden $(51,7 \%)$ mendapat dukungan yang cukup dari keluarga, dan 21 rsponden $(23,6 \%)$ mendapat dukungan yang kurang dari keluarga. Dari hasil penelitian ini dapat di asumsikan bahwa pasien DM yang berkunjung di Puskesmas Bendosari sebagian besar mendapatkan dukungan dari keluarga.

Berdasarkan hasil penelitian diatas sesuai dengan teori yang menyatakan bahwa Dukungan keluarga didefinisikan sebagai suatu faktor yang penting dalam kepatuhan manajemen penyakit kronik untuk remaja maupun dewasa. Dukungan keluarga merupakan indikator yang kuat yang dapat memberikan suatu dampak positif terhadap perawatan diri pada pasien dengan diabetes (Hensarling, 2009), karena dalam dukungan keluarga terdapat berbagai jenis dukungan keluarga yang sangat berpengaruh yaitu, Dukungan instrumental, yaitu keluarga merupakan sumber pertolongan ptaktis dan konkrit diantaranya : bantuan langsung dari orang yang diandalkan seperti materi, tenaga dan sarana. Manfaat dukungan ini adalah mendukung pulihnya energi atau stamina dan semangat yang menurun selain individu merasa bahwa masih ada perhatian atau kepedulian dari linkungan terhadap seseorang yang sedang mengalami kesusahan atau penderitaan sehingga dukungan instrumental ini sangat berpengaruh dengan keteraturan pasien dalam mengontrol kadar gula darah nya. Dukungan informasional yaitu keluarga berfungsi sebagai sebuah kolektor dan disseminator (penyebar informasi) tentang dunia yang dapat digunakan untuk mengungkapkan suatu masalah. Manfaat dari dukungan ini adalah dapat menekan munculnya suatu stressor karena informasi yang diberikan dapat menyumbangkan aksi sugesti yang khusus pada individu. Aspek-aspek dalam dukungan ini adalah nasehat, ususlan, saran, petunjuk dan pemberian informasi sehingga berhubungan dengan dukungan keluarga dalam mengontrol kadar gula darah pada penderita Diabetes Mellitus. Dukungan Penilaian (appraisal) yaitu keluarga bertindak sebagai sebuah umpan balik, membimbing dan menengahi pemecahan masalah dan sebagai sumber dan validator identitas keluarga. Dukungan emosional, yaitu keluarga sebagai sebuah tempat yang aman dan damai untuk istirahat dan pemulihan serta membantu penguasaan terhadap emosi. Manfaat dukungan ini adalah secara emosianal menjamin nilai-nilai individu (baik pria maupun wanita) akan selalu terjaga kerahasiannya dari keingintahuan orang lain. Aspek-aspek dari dukungan emosional meliputi dukungan yang diwujudkan dalam bentuk afeksi, adanya kepercayaan, perhatian dan mendengarkan serta di dengarkan .

Penderita diabetes mellitus sangat membutuhkan keempat jenis dukungan yang berasal dari keluarga sehingga diharapkan dapat mempercepat proses penyembuhan.

Dapat di asumsikan bahwa di wilayah kerja Puskesmas Mangasa keluarga yang kurang mendukung disebabkan berbagai faktor yang mempengaruhi adanya komplikasi yang diderita dan kurangnya nya perhatian keluarga kepada penderita diabetes mellitus, sementara itu sangatlah dibutuhkan perhatian yang cukup untuk mendukung keluarga yang memiliki penyakit diabetes mellitus dalam mengontrol kadar gula darahnya karena pada dasarnya dukungan keluarga sangat berpengaruh dalam mengontrol kadar gula darah karena dalam dukungan keluarga terdapat dukungan emosional, informasional, penghargaan atau penilaian dan instrumental. Dukungan emosional yang didapatkan dapat berupa mendengarkan setiap keluhan, keluarga menerima kondisi pasien dengan tidak merasa terbebani atau terganggu, dan juga dapat berupa suatu dukungan motivasi atau semangat kepada pasien saat pasien merasa cemas atau depresi sehingga pasien merasa nyaman dan berharga. Dukungan informasi yang di dapatkan dapat berupa suatu saran, nasehat, maupun pemberian informasi mengenai permasalahan yang di alami pasien atau informasi baru tentang Diabetes. Kemudian dukungan penghargaan atau penilaian yang di peroleh dapat berupa suatu support untuk mematuhi diet makanan sesuai anjuran dokter, dorongan untuk kontrol gula darah, teratur minum obat dan lain-lain. Sedangkan dukungan instrumental dapat berupa keluarga mengingatkan dan menyediakan makanan sesuai diet, membantu dalam biaya pengobatan pasien, mengantar pasien ke tempat pelayanan kesehatan dan lain-lain.

\section{b. Keteraturan Kontrol gula darah}

Berdasarkan hasil penelitian yang telah diperoleh dari 22 orang penderita diabetes mellitus di 
wilayah kerja Puseksmas Mangasa Kec.Rappocini Kota Makassar sebagian besar rutin untuk ke puskesmas untuk mengontrol kadar gula darahnya dengan kisaran 20 orang 909,9\%, sedangkan yang tidak teratur dalam mengontrol kadar gula darahnya berkisaran 2 orang $9,1 \%$. Hal ini menunjukkan bahwa sebagian besar dari penderita diabetes mellitus di wilayah Kerja Puskesmas Mangasa rutin untuk memeriksakan kadar gula darahnya.

Hal ini sesuai dengan hasil penelitian yang telah dilakukan oleh Priharianto dimana kebanyakan penduduk yang teratur untuk mengontrol kadar gula darahnya di Wilayah Puskesmas Bendosari adapun yang teratur melakukan kontrol kadar gula darah sebanyak 46 responden $(51,7 \%)$, dan responden yang tidak teratur melakukan kontrol kadar gula darah sebanyak 43 responden (48,3\%).

Berdasarkan hasil penelitian diatas sesuai dengan teori yang menyatakan bahwa melakukan kontrol adalah suatu keharusan semua penderita diabetes, ini tidak bisa dilepaskan dari kehidupannya untuk mencegah kemungkinan timbulnya komplikasi. pemeriksaan gula darah adalah satu-satunya jalan untuk mengetahui apakah pasien diabetes terkontrol dengan baik atau tidak. No news it not good news as a diabetic. Pemeriksaan gula darah sangat membantu dalam pengobatan dan pencegahan komplikasi, sehingga dalam melakukan kontrol gula darah harus dilakukan dengan disiplin (Tranda,2017).

Menurut Perkeni (2011) penatalaksanaan penderita DM antara lain salah satunya yaitu dengan evaluasi medis secara berkala yakni dengan melakukan pemeriksaan Kadar Glukosa secara teratur. Kontrol kadar gula darah ini dilakukan untuk mengevaluasi pengobatan yang telah dilakukan apakah telah mencapai sasaran dan juga untuk menyesuaikan dosis obat yang harus diminum. Dengan teratur kontrol kadar gula darah maka komplikasi dapat dicegah dan dapat di hambat.

Dapat di Asumsikan bahwa masih terdapat beberapa penderita Diabetes Melitus di Wilayah Kerja Puskesmas Mangasa Kec. Rappocini Kota Makassar teratur dalam mengontrol kadar gula darahnya disebabkan oleh adanya dukungan yang diberikan oleh masing-masing keluarga dan terdapat 2 yang tidak teratur mengontrol kadar gula darahnya disebabkan karena faktor umur penderita kurangnya dukungan keluarga kepada penderita hal ini juga dipengaruhi oleh faktor usia yang dimiliki penderita tersebut dan adanya komplikasi penyakit stroke dan TB yang diderita. Dukungan keluarga tersebut yaiu dukungan emosional, instrumental, penilaian atau penghargaan dimana hal tersebutlah yang mendorong penderita diabetes mellitus rutin dalam mengontrol kadar gula darahnya.

c. Hubungan Dukungan Keluarga Dengan
Keteraturan Kontrol Kadar Gula Darah
Berdasarkan hasil penelitian yang diperoleh dari 22 orang yang menderita diabetes mellitus di wilayah kerja Puskesmas Mangasa Kec.Rappocini Kota Makassar sebagian besar memiliki hubungan dukungan keluarga terhadap keteraturan kontrol kadar gula darah terhadap penderita diabetes mellitus dengan kisaran 20 orang dengan $100 \%$, dan terdapat 2 orang yang dukungan keluarganya tidak mendukung dan tidak teratur dalam mengontrol kadar gula darahnya.

Berdasarkan hasil penelitian diatas sesuai dengan teori yang menyatakan bahwa Dukungan keluarga dengan keteraturan kontrol kadar gula darah dimana dukungan keluarga adalah suatu faktor yang penting dalam kepatuhan manajemen penyakit kronik untuk remaja maupun dewasa. Dukungan keluarga merupakan indikator yang kuat yang dapat memberikan suatu dampak positif terhadap perawatan diri pada pasien dengan diabetes (Hensarling, 2009), karena dalam dukungan keluarga terdapat berbagai jenis dukungan keluarga yang sangat berpengaruh yaitu, Dukungan instrumental Manfaat dukungan ini adalah mendukung pulihnya energi atau stamina dan semangat yang menurun selain individu merasa bahwa masih ada perhatian atau kepedulian dari linkungan terhadap seseorang yang sedang mengalami kesusahan atau penderitaan sehingga dukungan instrumental ini sangat berpengaruh dengan keteraturan pasien dalam mengontrol kadar gula darah nya. Dukungan informasional yaitu keluarga berfungsi sebagai sebuah kolektor dan disseminator (penyebar informasi) tentang dunia yang dapat digunakan untuk mengungkapkan suatu masalah. Manfaat dari dukungan ini adalah dapat menekan munculnya suatu stressor karena informasi yang diberikan dapat menyumbangkan aksi sugesti yang khusus pada individu. Aspek-aspek dalam dukungan ini adalah nasehat, ususlan, saran, petunjuk dan pemberian informasi sehingga berhubungan dengan dukungan keluarga dalam mengontrol kadar gula darah pada penderita Diabetes Mellitus. Dukungan Penilaian (appraisal) yaitu keluarga bertindak sebagai sebuah umpan balik, membimbing dan menengahi pemecahan masalah dan sebagai sumber dan validator identitas keluarga. Dukungan emosional, yaitu keluarga sebagai sebuah tempat yang aman dan damai untuk istirahat dan pemulihan serta membantu penguasaan terhadap emosi. Manfaat dukungan ini adalah secara emosianal menjamin nilai-nilai individu (baik pria maupun wanita) 
Vol. 08. No.02. 2017

e-issn : 2622-0148, p-issn : 2087-0035

akan selalu terjaga kerahasiannya dari keingintahuan orang lain. Aspek-aspek dari dukungan emosional meliputi dukungan yang diwujudkan dalam bentuk afeksi, adanya kepercayaan, perhatian dan mendengarkan serta di dengarkan dan keteraturan kontrol gula darah adalah suatu keharusan semua penderita diabetes, ini tidak bisa dilepaskan dari kehidupannya untuk mencegah kemungkinan timbulnya komplikasi. pemeriksaan gula darah adalah satusatunya jalan untuk mengetahui apakah pasien diabetes terkontrol dengan baik atau tidak. No news it not good news as a diabetic. Pemeriksaan gula darah sangat membantu dalam pengobatan dan pencegahan komplikasi, sehingga dalam melakukan kontrol gula darah harus dilakukan dengan disiplin (Tardan,2017).

Hasil uji analisa hubungan dukungan keluarga dengan keteraturan kontrol kadar gula darah pada penderita diabetes mellitus di wilayah kerja Puskesmas Mangasa Kec.Rappocini Kota Makassar dengan menggunakan Chi Square di dapatkan nilai $p=0,004$ yang nilainya lebih kecil dari 0,05 maka dapat disimpulkan Ho ditolak, yang artinya ada hubungan dengan dukungan keluarga terhadap keteraturan kontrol kadar gula darah pada penderita diabetes mellitus diwilayah kerja Puskesmas Mangasa Kec.Rappocini Kota Makassar.

Hasil penelitian ini di dukung oleh penelitian Periharianto Hasil uji analisa hubungan dukungan keluarga dengan keteraturan kontrol kadar gula darah dengan menggunakan Chi-Square $\left(\mathrm{x}^{2}\right)$ didapatkan nilai $\left(x^{2}\right.$ hitung $\left.=9,363\right)$ dengan nilai probabilitas 0,009 yang nilainya lebih kecil dari 0,05 maka dapat disimpulkan bahwa Ho ditolak, yang artinya bahwa ada hubungan antara dukungan keluarga dengan keteraturan kontrol kadar gula darah pada penderita Diabetes Melitus di wilayah Puskesmas Bendosari.

Dapat diasumsikan bahwa hubungan dukungan keluarga dengan keteraturan kontrol kadar gula darah di wilayah kerja Puskesmas Mangasa Kec.Rappocini Kota Makassar Hasil uji analisa hubungan dukungan keluarga dengan keteraturan kontrol kadar gula darah pada penderita diabetes mellitus di wilayah kerja Puskesmas Mangasa Kec.Rappocini Kota Makassar dengan menggunakan Chi Square di dapatkan nilai $p=0,004$ yang nilainya lebih kecil dari 0,05 maka dapat disimpulkan Ho ditolak, yang artinya ada hubungan dengan dukungan keluarga terhadap keteraturan kontrol kadar gula darah pada penderita diabetes mellitus diwilayah kerja Puskesmas Mangasa Kec.Rappocini Kota Makassar.

\section{KESIMPULAN}

Berdasarkan uraian yang telah dijelaskan dapat disimpulkan sebagai berikut :

1. Sebagian besar $90,9 \%$ penderita diabetes mellitus di wilayah kerja Puskesmas Mangasa Kec.Rappocini Kota Makasar memiliki dukungan kelaurga yang mendukung

2. Sebagian besar $90,9 \%$ penderita dibetes mellitus di wilayah kerja Puskesmas Mangasa Kec.Rappocini Kota Makasar memiliki ketaraturan kontrol kadar gula daranya dengan baik

3. Terdapat hubungan yang bermakna antara hubungan dukungan keluarga dengan keteraturan kontrol kadar gula darah pada penderita diabetes mellitus di wilayah kerja Puskesmas Mangasa Kec.Rappocini Kota Makasar, dengan p<0,05

\section{SARAN}

Berdasarkan penemuan-penemuan masalah dalam penelitian ini, peneliti memberikan saran untuk :

1. Bagi peneliti selanjutnya diharapkan untuk mengembangkan penelitian yang serupa dengan memperhatikan kembali aspek pengaruh lain yang dapat mempengaruhi dukungan keluarga terhadap keteraturan kontrol kadar gula darah.

2. Bagi penderita diabetes mellitus tipe 2 untuk aktif dalam mengontrol kadar gulah darah untuk mengetahui perkembangan penyakit serta dapat meningkatkan kualitas hidup.

3. Bagi keluarga agar selalu mendampingi anggota keluarga yang mengahadapi masalah kesehatan serta memberikan dukungan moril dan spiritual selama proses dalam mengontrol kadar gula darah.

4. Bagi tenaga kesehatan dan institusi khususnya perawat agar terus memberikan Health Education pada penderita diabetes mellitus tentang penyakit diabetes mellitus serta manajemen Diabetes mellitus yang baik sehingga dapat meningkatkan derajat status kesehatan pada penderita diabetes mellitus.

\section{DAFTAR PUSTAKA}

Bilous, R., \& Donelly, R. (2014). Buku Pegangan Diabetes. Jakarta: Bumi Medika.

Damayanti, S. (2015). Diabetes Mellitus \& Penatalaksanaan Keperawatan. Yogyakarta: Nuha Medika.

Fady, M. (2015). Madu dan Luka Diabetik. Yogyakarta: Goysen Publishing.

Hidayat, A. (2017). Metodologi penelitian Keperawatan dan Kesehatan. Jakarta Selatan: Salemba Medika. 
Jurnal Media Keperawatan: Politeknik Kesehatan Makassar

Vol. 08. No.02. 2017

e-issn : 2622-0148, p-issn : 2087-0035

Harnilawati. (2013). Konsep Dan Proses Keperawatan Keluarga . Takalar: Pustaka As Salam.

Hensarling, J. 2009 Development and psychometric testing of hensarling's diabetes family support scale, a dissertation. Degree of Doctor of Philosophy in the Graduate school of the Texa's Women's University. Diakses dari www.proquest.com pada tanggal 5 April 2018.

Internasional diabetes federation 2015 online version of diabetes atlas seventh edition 2015 : http://www.org.at/pdf/1606ofatlas2015uk.Pdf (diakses 27 januari 2018).

Internasional diabetes federation 2017 online version of diabetes atlas eight edition 2017 : http:// diabtesasia.org./conten/diabetesguidelines/idfguidelines.pdf (diakses 27 januari 2018).

Nuari, N. (2017). Stratgi Manajemen Edukasi Pasien Diabetes Mellitus. Yogyakarta: Grup Penerbit CV BUDI UTAMA.

Nursalam. (2016). Metodologi Penelitian Ilmu Keperawatan . Jakarta : Salemba Medika.

Notoatmodjo, s. (2015). Metodologi Penelitian Kesehatan . Jakarta: Rineka Cipta.

Priharianto, A. (2014). hubungan antara dukungan keluarga dengan keteraturan kontrol kadar gula darah pada penderita diabetes melitus di wilayah puskesmas bendosarl sukoharjo.

Tarwoto, \& dkk. (2016). Keperawatan Medikal Bedah Gangguan Sistem Endokrin. Jakarta: CV. Trans Info Media.

Tandra (2017) Panduan Lengkap Mengenal dan Mengatasi Diabetes Melitus dengan Cepat dan Mudah. Jakarta: PT Gramedia Pustaka Utama.

Tarwoto, \& dkk. (2016). Keperawatan Medikal Bedah Gangguan Sistem Endokrin. Jakarta: CV. Trans Info Media.

Salindeho, A., Mulyadi, \& Rottie, J. (2016). Pengaruh Senam Diabetes Melitus Terhadap Kadar Gula Darah Penderita Diabetes Melitus Tipe 2 Di Sanggar Senam Persadia. ejournal Keperawatan , 4, 2.

Suprajitno. (2014). Asuhan Keperawatan Keluarga. Jakarta: Kedokteran EGC.

Soegondo, S., Soewondo, P., \& Subekti, I. (2015). Penatalaksanaan Diabetes Mellitus Terpadu. Jakarta: Badan Penerbit FKUI.

Syahrir, \& dkk. (2014). Profil Kesehatan Sulawesi Selatan 2014. http://www.depkes.go.id/resources/download/profil/PROFIL_KES_PROVINSI_2014/27_sulawesi_selatan_2014. pdf,p.69.diakses Selasa,30 Januari 2018,pukul 10:15.

Sari. R. N (2012). Diabetes Mellitus. Yogyakarta : Nuha Medika

Kemenkes RI (2013) riset kesehatan dasar. Jakarta : badan penelitian dan pengembangan kesehatan : http://www.depkes.go.id/resources/download/general/hasil\%20rikesdas\%20 201.Pdf (diakses 27 januari 2018)

Donsu, J, D. (2016). Metodologi Penelitian Keperawatan, Yogyakarta, Pustaka Baru Press 